\title{
KAJIAN INTERAKSI OBAT TERHADAP RESEP POLI PENYAKIT DALAM DI RSUD GUNUNG JATI CIREBON
}

\section{STUDY ON PRESCRIPTION DRUG INTERACTIONS IN POLY DISEASE IN RSUD GUNUNG JATI CIREBON}

\author{
Siti Pandanwangi TW ${ }^{\mathbf{1}}$, Nur Rahmi Hidayati ${ }^{\mathbf{1}}$ \\ ${ }^{1}$ Akademi Farmasi Muhammadiyah Cirebon \\ Jl. Cideng Indah no.3 Cirebon \\ Email: sitipandanwangitw@yahoo.com
}

\begin{abstract}
ABSTRAK
Interaksi obat adalah peristiwa dimana kerja obat dipengaruhi oleh obat lain yang diberikan bersamaan atau hampir bersamaan.Tujuan penelitian ini untuk mengetahui adanya interaksi obat dari peresepan obat, mengetahui hubungan antara jenis kelamin pasien terhadap peresepan obat,untuk mengetahui hubungan antara usia pasien obat terhadap peresepan obat dan untuk mengetahui hubungan antara jumlah resep dengan interaksi obat terhadap peresepan obat poli penyakit dalam di RSUD Gunung Jati Cirebon.Jenis obat dan penyakit dari resep yang diperoleh dari instalasi farmasi rawat jalan poli penyakit dalam RSUD Gunung Jati Cirebon Juli 2016, jumlah resep , Jenis kelamin pasien yang resepnya mengalami interaksi obat, usia pasien yang resepnya mengalami interaksi obat, Jumlah obat yang resepnya mengalami interaksi obat. Sample dalam penelitian ini sebanyak 333 resep. Data yang diperoleh dihitung dan divalidasi menggunakan Chi-Square. Berdasarkan hasil penelitian dapat ditarik kesimpulan terdapat interaksi obat dalam peresepan poli penyakit dalam RSUD Gunung Jati sebesar 46,546 \%.Berdasarkan analisa statistik bahwa tidak ada hubungan antara jenis kelamin dengan interaksi obat terhadap peresepan obat poli penyakit dalam, ada hubungan antara usia pasien dengan interaksi obat terhadap peresepan obat poli penyakit dalam dan ada hubungan antara jumlah obat dengan interaksi obat terhadap peresepan obat poli penyakit dalam di RSUD Gunung Jati Cirebon.
\end{abstract}

Kata kunci: Interaksi obat, resep, poli penyakit dalam.

\begin{abstract}
Drug interaction is an event in which the action of the drug is influenced by other drugs given concurrently or almost simultaneously. The purpose of this study is to determine the interaction of drugs from prescribing drugs, to know the relationship between the patient's sex to the prescription of drugs, to determine the relationship between the age of drug patients to prescribing drugs And to know the relation between prescription amount with drug interaction to prescribing medicine of poly disease in RSUD Gunung Jati Cirebon. Type of drug and disease from prescription obtained from pharmacy outpatient installation of poly disease in Gunung Jati Hospital Cirebon July 2016, prescription amount, Gender Patients whose prescriptions have drug interactions, the age of patients whose recipes have drug interactions, The number of drugs prescribed by drug interactions. Samples in this study were 333 recipes. The obtained data is calculated and validated using Chi-Square. Based on the research results can be concluded that there are drug interactions in the prescribing of poly disease in RSUD Gunung Jati is $46.546 \%$. Based on statistical analysis that there is no relationship between sex with drug interactions on the prescription of poly medicine in the disease, there is a relationship between patient age with drug interaction against The prescription of poly medicine in the disease and there is a relationship between the number
\end{abstract}


of drugs with drug interactions on the prescription of poly medicine in internal medicine at Gunung Jati Hospital Cirebon.

Keywords: drug interactions, prescription, poly medicine.

\section{PENDAHULUAN}

Interaksi obat adalah peristiwa dimana kerja obat dipengaruhi oleh obat lain yang diberikan bersamaan atau hampir bersamaan. Efek obat dapat bertambah atau berkurang karena interksi tersebut sehingga dapat terjadi dua kemungkinan yaitu dapat meningkatkan efek toksik atau efek samping atau berkurangnya efek klinik yang diharapkan. Biasanya hal tersebut terjadi pada pemberian obat polifarmasi, yaitu pengunaan obat lebih dari satu atau dua macam obat. Sehingga kemungkinan terjadinya interaksi obat sangat mungkin terjadi sehingga muncul masalah terkait obat (drug related problem) terkait interaksi obat. Dengan demikian merupakan fungsi, peran dan tanggung jawab famasis untuk dapat memahami dan menyadari serta mencegah dan mengatasi masalah terkait obat, salah satunya adalah interaksi obat.

Tujuan dari penelitian ini untuk mengetahui adanya interaksi obat dari peresepan obat Poli Penyakit Dalam RSUD Gunung Jati Cirebon, untuk mengetahui hubungan antara jenis kelamin pasien terhadap peresepan obat Poli Penyakit Dalam di RSUD Gunung Jati Cirebon, untuk mengetahui hubungan antara usia pasien obat terhadap peresepan obat Poli Penyakit Dalam di RSUD Gunung Jati Cirebon, untuk mengetahui hubungan antara jumlah resep dengan interaksi obat terhadap peresepan obat Poli Penyakit Dalam di RSUD Gunung Jati Cirebon.

\section{METODE PENELITIAN}

\section{Bahan}

Penelitian yang dilakukan oleh penulis adalah dengan metode analitis-deskriptis dengan desain case-control. Dengan pengambilan data secara retrospektif.Populasi pada penelitian ini adalah resep-resep di Instalasi Farmasi Rawat Jalan dari Poli Penyakit Dalam RSUD Gunung Jati Cirebon. Sampel dalam penelitian ini adalah, seluruh resep dari Instalasi Farmasi Rawat Jalan dari Poli Penyakit Dalam RSUD Gunung Jati yang menggunakan obat lebih dari 1 obat tiap resep.

\footnotetext{
Alat

Alat peneltian yang digunakan adalah resep, dan aplikasi medscape

\section{Jalannya Penelitian}

Peneliti mengambil data berupa resep dari Instalasi Farmasi Poli Penyakit Dalam RSUD Gunung Jati Cirebon, Skrining Resep, Indentifikasi interaksi obat berdasarkan literature, Mencatat semua hasil penelitian berdasarkan data resep yang ada, Memasukan ke dalam aplikasi Medscape.

Jenis obat dan penyakit dari resep yang diperoleh dari Instalasi Farmasi Rawat Jalan Poli Penyakit dalam RSUD Gunung Jati Cirebon Bulan Juli 2016, Jumlah resep pasien Poli Penyakit Dalam, Jenis kelamin pasien Poli Penyakit Dalam yang resepnya mengalami interaksi obat, Usia pasien Poli Penyakit Dalam yang resepnya mengalami interaksi obat, Jumlah obat pasien Poli Klinik yang resepnya mengalami interaksi obat. Sample dalam penelitian ini sebanyak 333 resep.
} 


\section{Analisa Data}

Data yang diperoleh dari hasil penelitian dihitung dan divalidasi secara statistic dengan menggunakan rumus Chi-Square/ Kai Kuadrat. Merupakan satu jenis uji komparatif non parametris yang digunakan pada dua variabel, dimana skala data kedua variable adalah nominal .

$$
\text { Chi Square Hitung }=\sum \frac{(f o-f e)^{2}}{f e}
$$

Keterangan :

fo $=$ frekuensi observasi, dan

$\mathrm{fe}=$ frekuensi harapan

(www.statistik.com>home>komparatif $>$ rumus)

\section{HASIL DAN PEMBAHASAN}

Tabel I Jumlah resep yang mengalami interaksi obat

\begin{tabular}{lll}
\hline Pasien & Jumlah & \% \\
\hline Resep dengan inteaksi obat & 155 & 46.546 \\
Resep tanpa interaksi obat & 178 & 53.454 \\
Jumlah & 333 & 100 \\
\hline
\end{tabular}

Tabel II Jenis kelamin pasien yang mengalami interaksi obat

\begin{tabular}{lllll}
\hline $\begin{array}{l}\text { Jenis } \\
\text { Pasien }\end{array}$ & Kelamin & $\begin{array}{l}\text { Jumlah } \\
\text { resep }\end{array}$ & $\begin{array}{l}\text { Jumlah resep yang } \\
\text { mengalami } \\
\text { obat }\end{array}$ & $\begin{array}{l}\text { \% } \\
\text { interaksi }\end{array}$ \\
\hline Pria & & 53 & & 44.915 \\
Wanita & 118 & 53 & 47.441 \\
Jumlah & 215 & 102 & 46.546 \\
\hline
\end{tabular}

Tabel III Jenis kelamin pasien yang tidak mengalami interaksi obat

\begin{tabular}{|c|c|c|c|c|}
\hline Jenis & Kelamin & Jumlah & Jumlah resep yang tidak & $\%$ \\
\hline Pasien & & Resep & $\begin{array}{l}\text { mengalami interaksi } \\
\text { obat }\end{array}$ & \\
\hline Pria & & 118 & 65 & 55.085 \\
\hline Wanita & & 215 & 113 & 52.558 \\
\hline Jumlah & & 333 & 178 & 53.454 \\
\hline
\end{tabular}

Tabel IV Usia pasien yang mengalami interaksi obat

\begin{tabular}{|c|c|c|c|}
\hline Kelamin & Jumlah & Jumlah resep yang & $\%$ \\
\hline Pasien & Pasien & $\begin{array}{l}\text { mengalamin interaksi } \\
\text { obat }\end{array}$ & \\
\hline Anak $(12<)$ & 1 & 0 & 0 \\
\hline Remaja (12-25) & 8 & 1 & 12.5 \\
\hline Dewasa (26-45) & 19 & 5 & 26.316 \\
\hline Lansia $(46>)$ & 305 & 149 & 48.852 \\
\hline Jumlah & 333 & 155 & 46.546 \\
\hline
\end{tabular}


Tabel V Usia pasien yang tidak mengalami interaksi obat

\begin{tabular}{|c|c|c|c|}
\hline Kelamin & Jumlah & Jumlah resep yang tidak & $\%$ \\
\hline Pasien & Pasien & $\begin{array}{l}\text { mengalamin interaksi } \\
\text { obat }\end{array}$ & \\
\hline Anak $(12<)$ & 1 & 1 & 100 \\
\hline Remaja (12-25) & 8 & 7 & 87.5 \\
\hline Dewasa (26-45) & 19 & 14 & 73.684 \\
\hline Lansia (46 >) & 305 & 156 & 51.147 \\
\hline Jumlah & 333 & 178 & 53.454 \\
\hline
\end{tabular}

Tabel VI Jumlah obat dalam resep yg mengalami interaksi obat

\begin{tabular}{|c|c|c|c|c|}
\hline $\begin{array}{l}\text { Jenis } \\
\text { Pasien }\end{array}$ & Kelamin & $\begin{array}{l}\text { Jumlah } \\
\text { Pasien }\end{array}$ & $\begin{array}{l}\text { Jumlah resep yang } \\
\text { mengalami ininteraksi } \\
\text { obat }\end{array}$ & $\%$ \\
\hline 1 obat & & 11 & 0 & 0 \\
\hline 2 obat & & 43 & 5 & 211.627 \\
\hline 3 obat & & 59 & 23 & 38.983 \\
\hline 4 obat & & 77 & 31 & 40.259 \\
\hline $5>$ & & 143 & 96 & 67.133 \\
\hline Jumlah & & 333 & 155 & 46.546 \\
\hline
\end{tabular}

Tabel VII Jumlah obat dalam resep yang tidak mengalami interaksi obat

\begin{tabular}{|c|c|c|c|c|}
\hline \multirow{2}{*}{$\begin{array}{l}\text { Jenis } \\
\text { Pasien }\end{array}$} & \multirow[t]{2}{*}{ Kelamin } & \multirow{2}{*}{$\begin{array}{l}\text { Jumlah } \\
\text { Pasien }\end{array}$} & Jumlah resep yang tidak & \multirow[t]{2}{*}{$\%$} \\
\hline & & & $\begin{array}{l}\text { mengalami interaksi } \\
\text { obat }\end{array}$ & \\
\hline 1 obat & & 11 & 11 & 100 \\
\hline 2 obat & & 43 & 38 & 88.372 \\
\hline 3 obat & & 59 & 36 & 61.017 \\
\hline 4 obat & & 77 & 46 & 59.740 \\
\hline $5>$ & & 143 & 47 & 32.867 \\
\hline Jumlah & & 333 & 178 & 53.454 \\
\hline
\end{tabular}

Dari data penelitian yang di dapat sebanyak 333 resep terdapat 155 resep yang terjadi interaksi obat dengan persentase sebesar 46,546 \%, sedangkan resep yang tidak terdapat interaksi obat sebanyak 178 resep dengan persentase sebesar 53,454 \%. Hampir separuh atau $50 \%$ dari total sampel resep terjadi interaksi obat. Pada penggolongan interaksi resep berdasarkan jenis kelamin, jumlah pasien dengan jenis kelamin wanita lebih banyak dibanding pria yaaitu sebanyak 215 pasien dengan resep yang terjadi interaksi obat sebanyak 102 pasien wanita dengan persentase sebesar $47,441 \%$, hampir separuh resep pasien wanita 
megalami interaksi obat. Pada pasien pria dengan jumlah 118 pasien terdapat 53 pasien pria yang mendapat resep yang mengalami interaksi dengan persentase sebesar 44,915\%, hampir separuhnya juga mengalami interaksi obat. Secara keseluruhan berdasarkan perhitungan statistik dengan menggunakan Chi-square didapat hasil $\mathrm{H}_{\mathrm{o}}$ diterima karena $\mathrm{p}$-value dari chi square $(0.658)>(\alpha=0.05)$, sehingga dapat disimpulkan bahwa tidak ada hubungan antara jenis kelamin dengan interaksi obat.

Pada pengelompokan berdasarkan usia yang dikategorikan dengan pasien anak, remaja, dewasa dan lansia. Pada kategori ini jumlah pasien terbanyak adalah pasien lansia dengan jumlah pasien sebanyak 305 pasien dan resep yang mengalami interaksi obat sebanyak 149 pasien dengan persentase $48,852 \%$. Sedangkan pada usia anak terdapat hanya 1 pasien dan resepnya tidak mengalami interaksi obat, pada pasien remaja dengan jumlah 8 pasien, hanya satu pasien yang resepnya mengalami interaksi obat dengan persentasi sebesar $12,5 \%$. Pada pasien dewasa dengan jumlah pasien sebanyak 19 terdapat 5 resep yang mengalami interaksi obat dengan persentase sebesar $23,316 \%$. Hasil perhitungan statistik menggunaka Chisquare didapatkan hasil $\mathrm{H}_{\mathrm{o}}$ ditolak karena p-value dari chi square $(0.039)<(\alpha=0.05)$ sehingga dapat disimpulkan bahwa ada hubungan antara usia pasien dengan interaksi obat.

Dari data penelitian dengan pengelompokan berdasarkan jumlah obat dalam setiap resep, terdapat 11 pasien dengan jumlah obat satu macam dalam satu resep, tentu saja tidak ada interaksi obta yang terjadi. Pada kategori resep dengan 2 macam obat didapat pasien sebanyak 43 pasien dengan 5 resep yang mengalami interaksi obat dengan persentase sebesar $38,983 \%$. Pada pasien yang mendapat resep 3 macam obat terdapat 59 pasien dengan jumlah 23 resep mengalami interaksi obat dengan persentase $61,740 \%$. Sedangkan pasien dengna 4 macam obat dalam satu resep sebanyak 77 pasien dengan 46 resep yang mengalami interaksi obat dengan persentase sebesar 40,259 \%. Dan yang terakhir resep dengan lebih dari 5 macam obat dengan jumalh pasien sebanyak 143 pasien dengan resep sebanyak 96 pasien yang mengalami interaksi obat dengan persentase 67,133\%. Berdasarkan perhitungan statistik menggunakan Chi-square di dapatkan hasil bahwa $\mathrm{H}_{\mathrm{o}}$ diterima karena p-value dari chi square $(0.000)>(\alpha=0.05)$ sehingga dapat disimpulkan bahwa ada hubungan antara jumlah obat dengan interaksi obat.

Dengan demikian dari hasil hasil penelitian terdapat interaksi dalam peresepan di Poli Penyakit Dalam di Rumah Sakit Umum Daerah Gunung Jati Cirebon 46,546 \%. Dengan perhitungan statistik menggunakan Ci-square didapat hasil bahwa tidak ada hubungan antara jenis kelamin dengan interaksi obat, ada hubungan antara usia pasien dengan interaksi obat da nada hubungan antara jumlah obat dalam resep dengan interaksi obat.

\section{KESIMPULAN}

Berdasarkan hasil penelitian yang telah dilakukan, dapat ditarik kesimpulan Terdapat interaksi obat dalam peresepan pada Poli penyakit Dalam RSUD Gunung Jati Cirebon sebesar 46,546 \%, Dengan perhitungan statistik menggunakan rumus Chi-Square dihasilkan kesimpulan bahwa tidak ada hubungan antara jenis kelamin dengan interaksi obat terhadap peresepan obat Poli Penyakit Dalam di RSUD Gunung Jati Cirebon, Ada hubungan antara usia pasien dengan interaksi obat terhadap peresepan obat Poli Penyakit Dalam di RSUD Gunung Jati Cirebon., Ada hubungan antara jumlah obat dengan interaksi obat terhadap peresepan obat Poli Penyakit Dalam di RSUD Gunung Jati Cirebon.

\section{DAFTAR PUSTAKA}

Ansari, JA 2010. Drug Interaction and Pharmacist. New Delhi : Journal of Young Pharmacist vol 2 No.3 Bushra Rabia, Nousheen Astan, Arshad Yar Khan 2015

Arikunto Suharsimi. 2005. Manjemen Penlitian. Jakarta : Rineka Cipta.

Arikunto Suharsimi. 2010. Prosedur Penelitian: Suatu Pendekatan Praktis, edisi revisi 2010. Jakarta : Rineka Putra. 
Ashraf Mozayani and Lionel P.aymon, Handbook of druginteractions: A Clinical and Forensicguide, 2004.

Ganiswara, G. Sulis, Farmakologi dan Terapi. Jakarta: Departemen Farmakologi dan Terapeutik Fakultas Kedokteran UI, 1995, Edisi IV.

Harkness, Richard, R.PH. Interaksi obat : Bandung. ITB 1989.

Ivan stockley, B. Pharm, PhD, MPS: Drug interactions and their mechanism: firs published in the phannaccutical journal, 1974

Kepmenkes No.1027/MENKES/SK/IX/2004 tentang Standar Pelayanan Kefarmasian di Apotek

Lacy F. Charles and partner. 2009. Drug Information Handbook. America: Lexicomp's.

Medscape.com. Drug Interaction Checker. Available :http://reference.medscape.com/druginteractioncheck

Permenkes No. 58 tahun 2014 tentang Standar Pelayanan Kefarmasian di Rumah Sakit

Riduwan. 2005. Belajar Mudah Penelitia Untuk Guru, Karyawan dan Peneliti Pemula. Bandung :Alfabeta.

Setiawati, 2007. Interaksi Obta. Dalam Buku :Sulistia Gan Gunawan, Riyanto Setiabudy, Nafriyadi, Elysabeth, Editor. Farmakologi dan Terapi Edisi 5. Jakrta : Departemen Farmakologi dan Terapeutik FKUI.

Sudjana, 2006. Pengantar Evaluasi Pendidikan. Bandung : Raja Grafindo Persada.

Sugiyono. 2007. Metode Penelitian Administrasi. Bandung: Alvabeta.

Sunyoto Danang dan Setiawan Ari. 2013. Buku Ajar : Statistik Kesehatan. Yogyakarta: Nuha Medika.

Tatro, Editor, 2009. Drug Interaction Fact. Fifth Edition. United States of America. Walters Kluwer Company.

Thanacoody, 2012. Drug Interaction. Dalam Buku: Walker R dan Whittlesea,Editor. Clinical Pharmacy and Therapeutics. Fifth Edition. London :Churchil Livingstone Elsevier.

Uma Sekaran. 2006. Metode Penelitian Bisis. Jakarta :Salemba empat.

www.statistik.com>home>komparatif $>$ rumus 